\title{
Formation of Adolescent Social Competence
}

\author{
Ramilya Sh. Kasimova*1, Gulnara F. Biktagirova ${ }^{2}$ \\ ${ }^{1,2}$ Kazan Federal University, Institute of Psychology and Education \\ *Email: kasimovlar@mail.ru
}

\section{Received: 21st October 2017 Accepted: 16th November 2017, Published: 31st December 2017}

\begin{abstract}
The article presents the results of the study aimed at adolescent social competence development. The conduct of this study was conditioned by the fact that the prosperity and the success of a modern man depends on the ability to solve problems, on his awareness of social space issues, the degree of social competence development that make it possible to achieve the desired goals and come to a necessary result. In the framework of this study, psychopedagogical literature was analyzed, various approaches were identified to define the notion of "social competence", the age characteristics of adolescents were identified, the diagnostic tools were selected ("The scale of social competence" by A.M. Prikhozhan, "The methodology for student socialization study by M.I. Rozhkov, G. Gilford's "Social Intelligence Test"). The study was conducted on the basis of the school in Kazan. 30 teenagers took part in the experiment ( 15 boys, 15 girls) at the age of 13-14. Based on the generalization of theoretical knowledge concerning the formation of social competence, taking into account the age characteristics of adolescents and obtained empirical data, we compiled a psycho-pedagogical program. The program included organized forms and the methods of work on the development of lagging indicators of adolescent social competence, it was conducted once a week for 45 - 50 minutes in a classroom and after-hours.

The effectiveness of the program was checked at the control stage of the study, it was checked by the methods of mathematical statistics and was described in detail in the article. The results and recommendations can be used in the practice of social educators, educators - psychologists, class leaders and tutors.
\end{abstract}

Keywords: Social Intelligence, Competence, SelfConfidence, Communicative Ability, Independence, Communication Ability, The Ability to Organize, Responsibility

\section{Introduction}

At present, the prosperity and the success of a modern man is in direct relationship with the ability to solve problems, with his knowledge about social space issues, with the degree of social competence development that enable him to achieve the desired goals and come to the necessary result. The mastering social competencies allows school leavers to take responsibility actively, to take part in the development of a common solution, to be able to resolve conflict situations in a positive way, to participate in the activities of various democratic institutions effectively" (2, p. 298).

Social competence is, above all, social activity, the desire to live in society, some motivation. In modern social and pedagogical science various aspects of social competence development are considered (E.V. Koblyanskaya [20], V.N. Kunitsyna [10], A. Kidron [7], E.A. Boyarsky [1]). Some studies deal with the structure, methodology, the diagnosis of social competence, the ways and the means of its development (N.V. Kalinina [6], M.I. Lukyanova [11]), L.M. Ivanov [5], I.A. Zimnaya [4], N.A. Dobrolyubov [3], L.S. Kolmogorova [9]).

\section{Materials and Methods}

The performed analysis of the literature revealed the ambiguity of the term "social competence" interpretation. Domestic psychological and pedagogical literature had mainly the communicative aspects predominated in the definition of "social competence". E.V. Koblyanskaya defines social competence as "relationship "I" - society understanding, the ability to choose the right social reference points, the ability to organize one's own activities in accordance with these guidelines [8, p. 19].

Nowadays, you can see that social competence is often compared with the notion of "self-confidence". According to G.I. Sivkova, "social competence is the presence of confident behavior, at which various skills in the sphere of relations with people are automated and give the opportunity to change their behavior flexibly depending on the situation" $[13$, p. 8].

In our study, we adhered to the definition of social competence, proposed by I.A. Maslova: "This is an integrative personal education, including knowledge, skills, abilities and skills that are formed in the process of socialization and allow a person to adapt quickly and adequately in society and interact with the social environment efficiently" [12, p. 4].

\section{Results and Discussion}

At the first stage the diagnosis was performed using three methods:

In order to determine the overall level of social competence development among adolescents, the "Scale of Social Competence" (A.M. Prikhozhan) was used. The questionnaire is a one-dimensional scale consisting of 36 statements combined into 6 sub-skills: 
1. The level of independence is a teenager's ability to set a goal on his own initiative, to find the ways to achieve it and to implement the decisions that he has taken in practice;

2. The level of self-confidence - determines the positive experience of social problem solution and the successful achievement of one's own goals, the satisfaction of needs;

3. The level of attitude to own duties - this scale determines the level of duty understanding by an adolescent and the ability to responsible in this regard;

4. The level of communication development - the level of adolescent communicative skills in accordance with age characteristics;

5. The level of organization - this scale shows the level of attention, concentration and mental activity concentration organization, the coverage of a number of objects when you operate with them, a close relationship of volume, the distribution and the switching of attention;

6. The level of interest in social life - it measures the level of adolescent interaction activity at school and in social life.

Initially, the general level of adolescent social competence was analyzed according to the "Scale of Social Competence" by A.M. Prikhozhan.

These studies show that $60 \%$ (18 people) have a standard level of social competence, $10 \%$ (3 people) of students are ahead of their peers concerning the development of social competence, $20 \%$ (6 people) have a slight lag in the development of social competence, and 10\% (3 people) have a significant lag in the development of social competence.

The sub-scale "Independence" showed that more than half of the subjects had the level of independence corresponding to the norm, we also observe slight fluctuations in the direction of excess and deviation from the norm, there were no students with a significant backlog in this sub-scale.

According to "Self-confidence" subscale 40\% (12 people) have a standard level of self-confidence, and a significant gap is observed among 27\% (8 people), which certainly draws our attention and requires further development.

The subscale "The attitude to their duties" shows that $67 \%$ (20 people) demonstrate a normal level of attitude to their duties, $15 \%$ (4 people) have a slight deviation from the norm, $13 \%$ (4 people) are above the norm and $5 \%$ (2 people) have a significant backlog in relations to their duties.

According to the subscale "Communication development" $50 \%$ (15 people) of the diagnosed have normal indicators, $34 \%$ have a slight deviation, $12 \%$ exceed the norm, and there is a significant lag in the development of communication among $4 \%$.
The subscale "Organization, development of arbitrariness" reveals a normal level of organization among $60 \%$ (18 people), a slight deviation from the norm among $25 \%$ ( 6 people), an excess of the norm among $15 \%$ (4 people), and a considerable gap among 2 people.

The subscale "Interest in social life" shows us almost the same results as the previous subscale: $60 \%$ (18 people) - norm, $20 \%$ (6 people) - a slight deviation from the norm, $15 \%$ (4 people) - an excess of the norm and $5 \%$ ( 2 people) - a significant gap from the norm.

According to the results of the points scored by the subjects, it can be concluded that basically the level of social competence corresponds to the norm, but there are deviations in the development of social competence, and this requires further work.

2. The methodology to study the socialization of personality by M.I. Rozhkova, to assess the level of social adaptation development, as the component of adolescent social competence.

The results of this methodology are presented below:

Based on the results of the diagnosis, it can be determined that, on the whole, the level of social adaptation corresponds to the norm, and there are fluctuations, as in the previous method. In terms of percentage $67 \%$ (20 people) have an average degree of socialization, $23 \%$ ( 7 people) have a high degree of social development and 10\% (3 people) have a low level of social adaptation.

3. Test "Social Intelligence" by J. Guilford. We used the 4th subtest of "History with the addition" to determine social intelligence. Each story consists of four pictures, one of which is always omitted. A subject must understand the logic of development, the plot of the story and to find the missed picture among four other ones offered for the answer.

The subtest measures the cognition factor of behavioral systems, namely the ability to understand the logic of interaction situation development and the significance of people's behavior in these situations.

These studies show that only $3 \%$ (one child) has a high ability to cognize behavior, $17 \%$ (5 children) have indicators above the average, $27 \%$ ( 8 people) have moderate abilities, 33\% (10 children) below average, $20 \%$ (6 children) have low abilities.

Thus, according to three performed methods, we can see that for some indicators adolescents have inadequate results corresponding to their age, namely: the ability to cognize behavior (social intelligence), self-confidence, and the development of communication. This means that further activities are necessary to improve the results of these indicators, and it is the aim of the program developed by us.

The program developed by us included specially organized forms and methods of work on the 
development of lagging indicators of adolescent social competence and consists of the sessions that are held once a week for 45 to 50 minutes during school time and after hours.

\section{Conclusions}

After the conduct of the formative experiment, repeated diagnostics of adolescents was carried out, in which the signs of incompatibility with the age-specific features of social competence level by certain indicators (selfconfidence, the development of communication, and the ability to cognize behavior (social intelligence) were revealed earlier.

The same methods were used for its implementation: the "Scale of Social Competence" by A.M. Prikhozhan, "The Methodology to Study the Student Personality Social Skills" by M. I. Rozhkov, and "The Social Intellect" by Guilford.

Following the results of A. Prikhozhan's diagnosis, the following results were obtained:

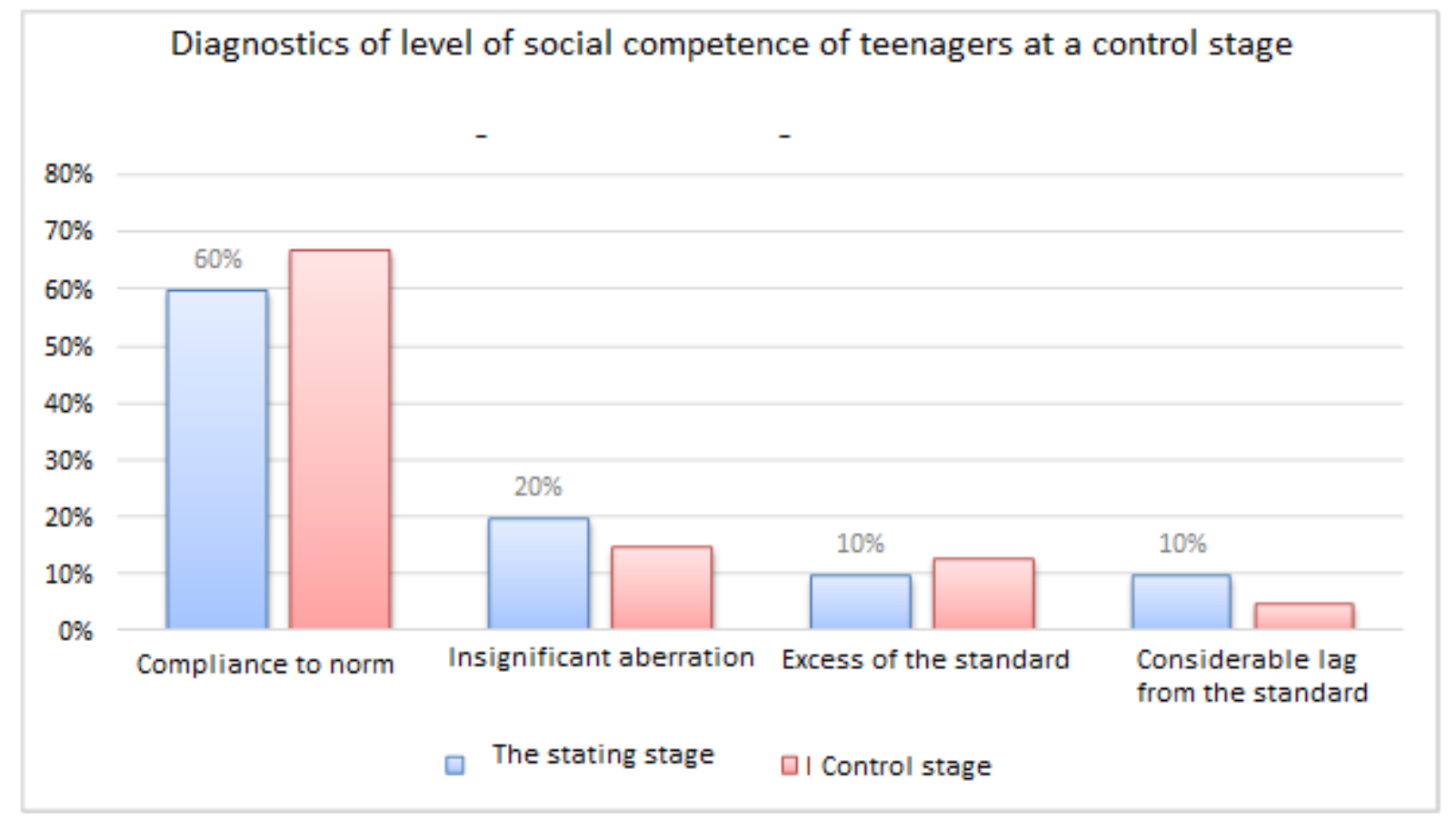

Fig. 2.10 - The scale of social competence (A.M. Prihozhan).

The data of the secondary diagnostics show that the number of adolescents whose social competence level corresponds to the norm has increased from $60 \%$ (18 people) to $67 \%$ (20 people), the number of students who are 10 times ahead of their peers in social competence development has increased from $10 \%$ (3 up to $13 \%$ (4 people), $20 \%$ (6 people) of those with a small gap in the development of social competence were reduced to $15 \%$ (4 people), and a significant development gap in social competence is now being observed only among $5 \%$ ( 1 person), previously there were $10 \%$ - 3 people.
If you analyze the subscales, the results are the following ones:

On the sub-scale "Independence" the norm has remained the same - 60\% (18 people), and the number of diagnosed persons who previously showed a slight lag in the development of social competence has decreased from $29 \%$ (9 people) to $23 \%$ (7 people) and the number of students with an elevated level of social competence has increased to $17 \%$ (5 people). 


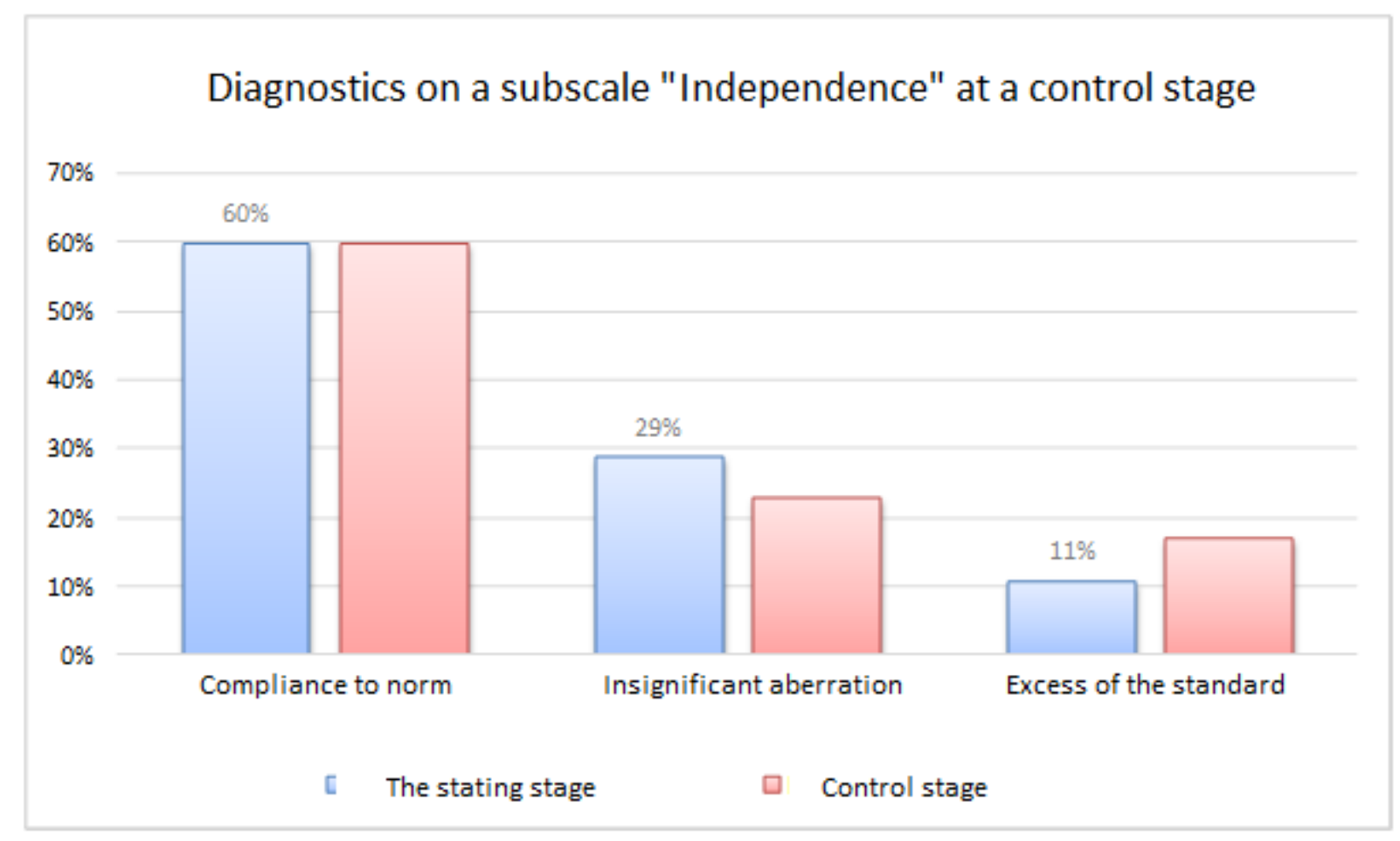

Fig.2.11 - «Social Competence Scale» (A.M. Prikhozhan), subscale "Independence”

The indicators of the subscale "Attitude to their duties" remained the same ones: $67 \%$ (20 people) correspond to the standard, $15 \%$ (4 people) with a slight deviation from the standard, $13 \%$ (4 people) exceed the standard and $5 \%$ ( 2 people) have a significant lag from the standard.

\section{Diagnostics on an indicator "The relation to the duties" at a control stage}

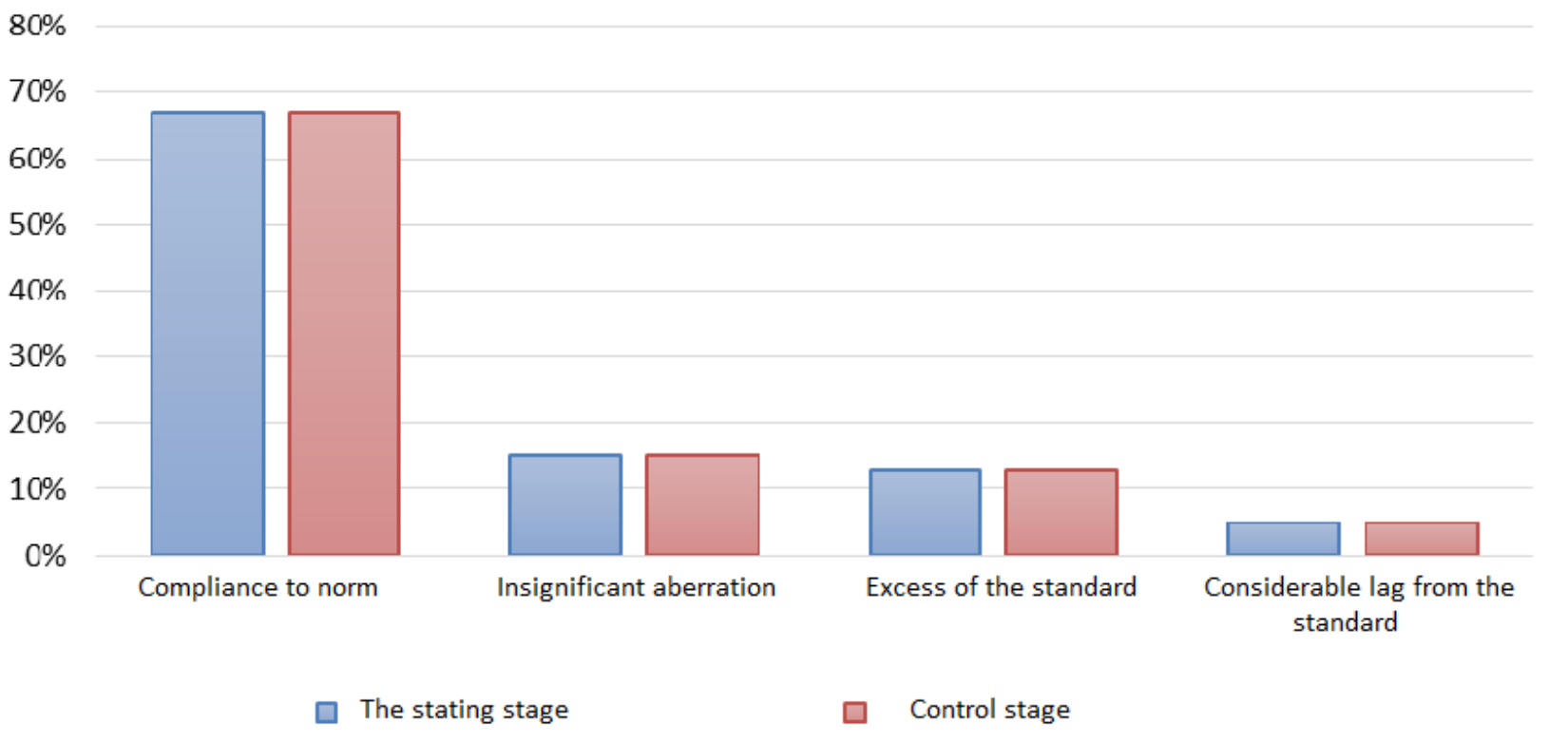

Fig.2.12 - "Social Competence Scale" (A.M. Prikhozhan), subscale "Attitude to own duties" 
The subscale "Organization, development of arbitrariness" has not changed its indicators.

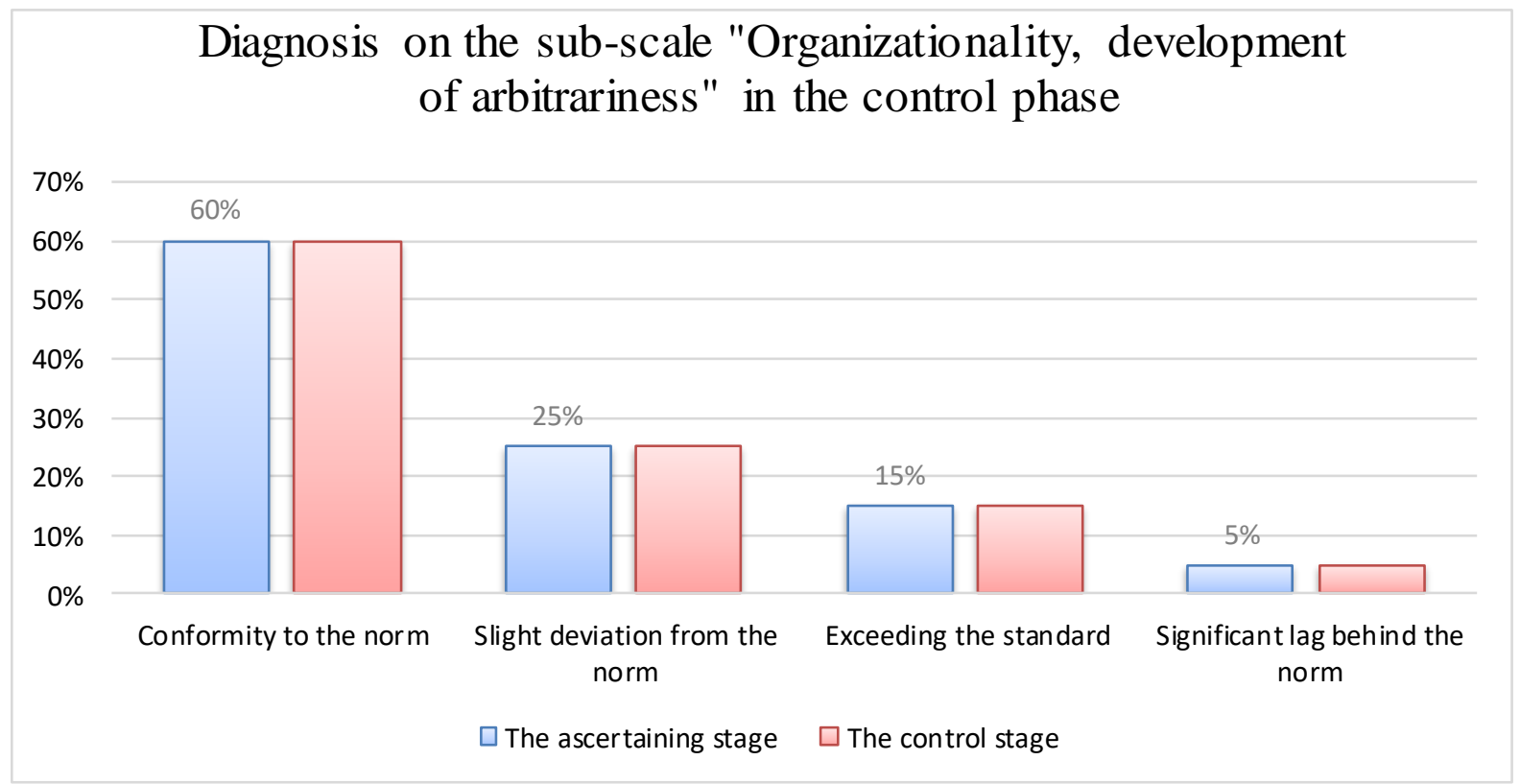

Fig. 2.13 - "The Scale of Social Competence" (A.M. Prikhozhan), subcategory "Organization, the development of arbitrariness"

According to the sub-scale "Interest in social life" the positive changes among the diagnosed ones with a significant lag from social competence development. The indicator of 5\% (2 people) dropped to $3 \%$ (1 person). The students with a slight lag, had the percentage decrease from $20 \%$ (6 people) to $15 \%$ (4 people), and the excess of the norm made $22 \%$ (7 people).

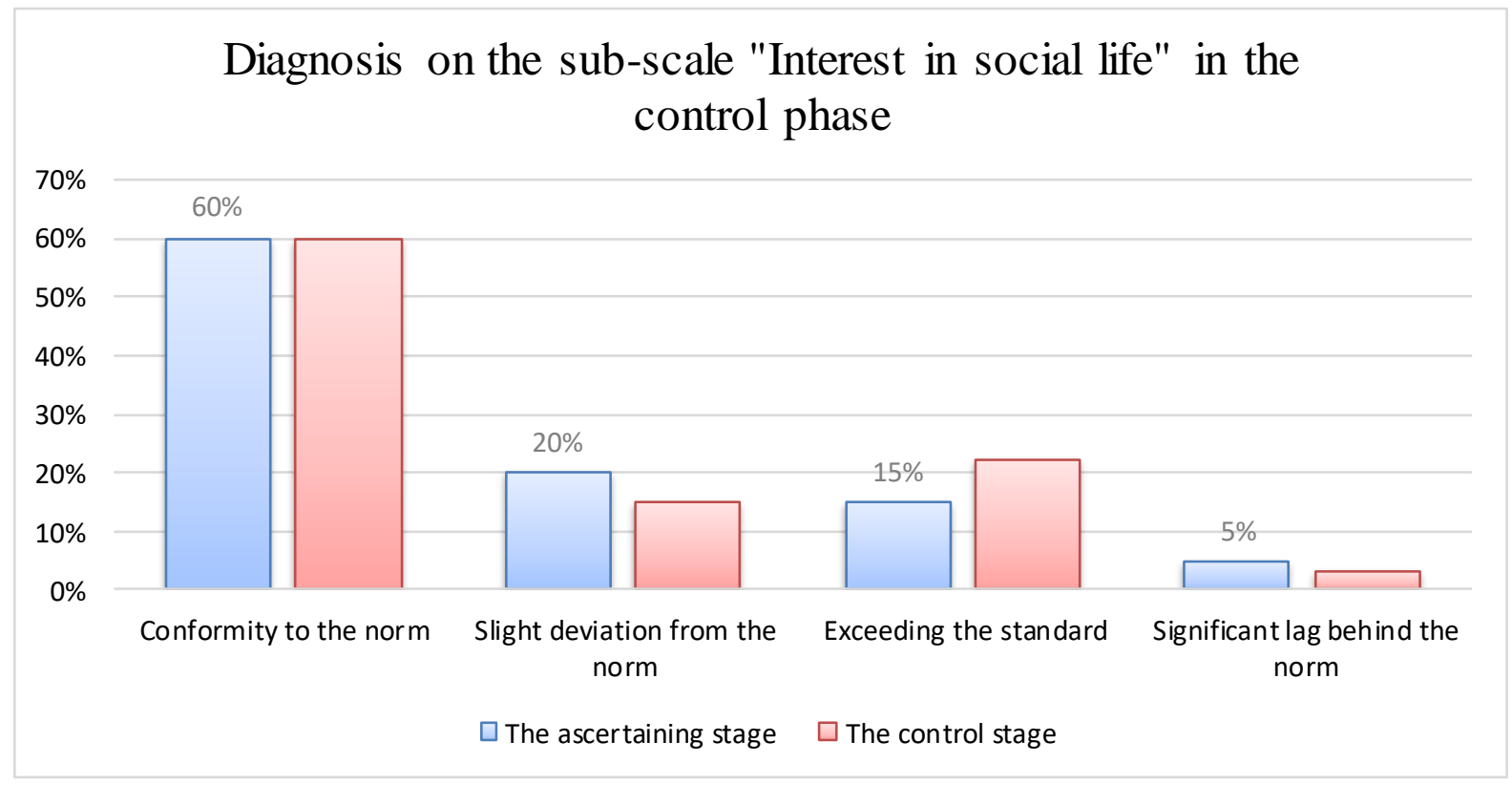

Fig.2.14 - "The scale of Social Competence" (A.M. Prikhozhan), subcategory "Interest in social life".

The results of the diagnosis according to the "Methodology for the study of a student's personality socialization" were the following ones. 


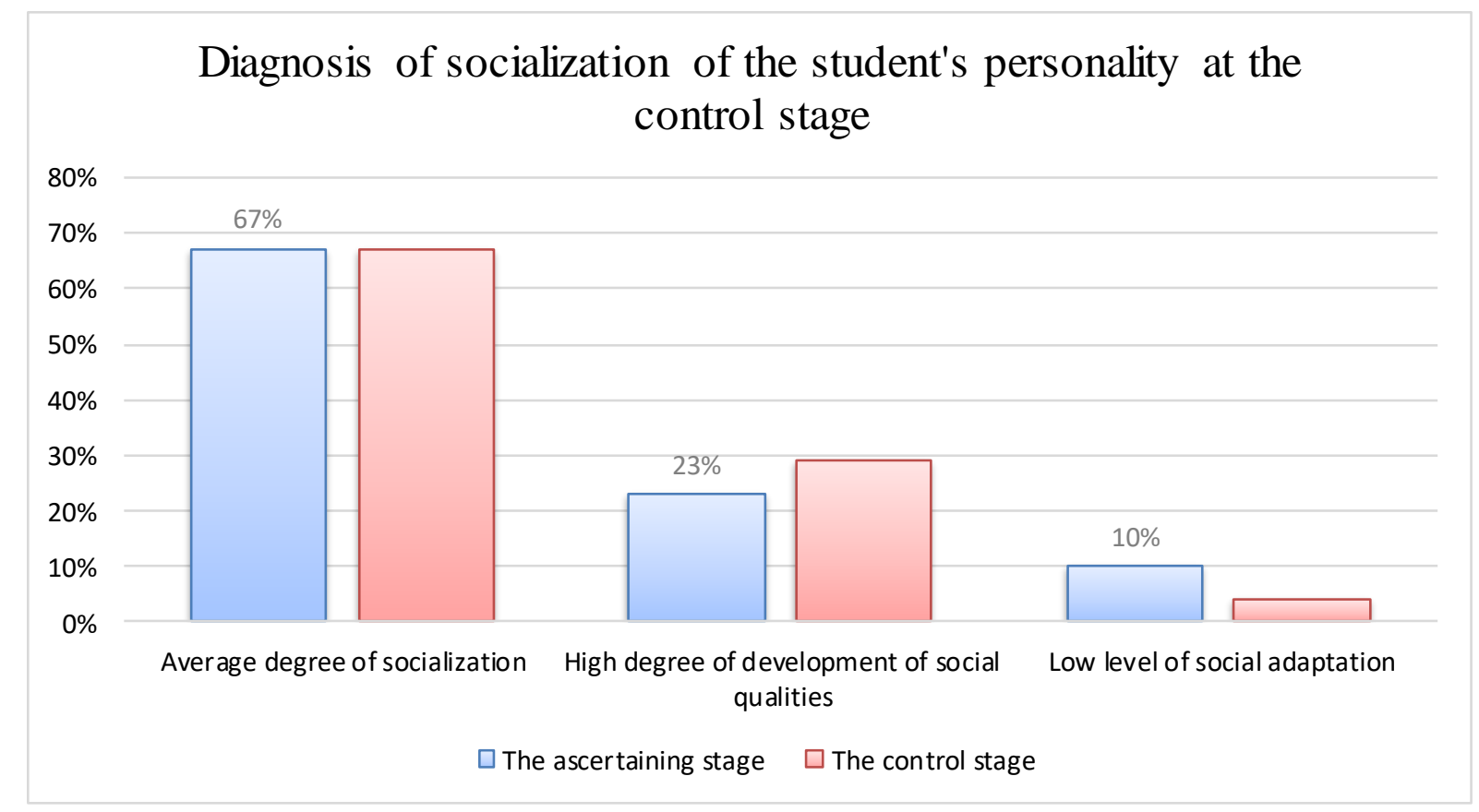

Fig. 2.15 - The Technique to Study the Socialization of a Student's Personality (M.I. Rozhkov).

After the second diagnosis, it was found that $67 \%$ (20 people), as in the stating diagnosis, have an average degree of socialization, the number of students with a high degree of social development increased from $23 \%$ (7 people) to $29 \%$ (9 people), and the number of students with low level of social adaptation has decreased from $10 \%$ (3 people) to $4 \%$ ( 1 person).

Based on the results of the diagnosis using the method by A. M. Prikhozhan according to the subscale "Selfconfidence", the following results were obtained.

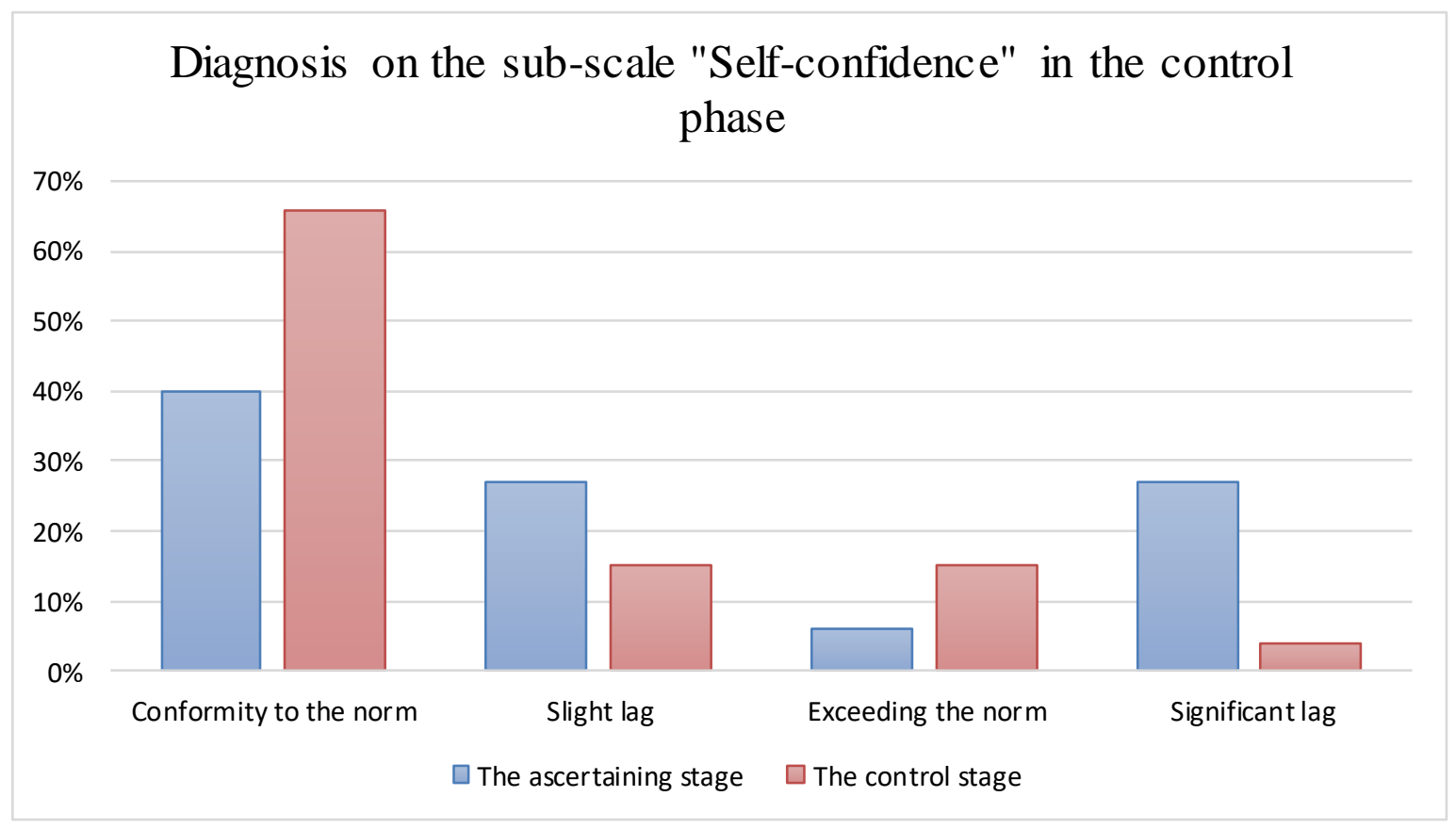

Fig.2.16 - "Social Competence Scale" (A.M. Prikhozhan), subscale "Self-confidence"

This indicator shows some positive dynamics, the level of social competence, corresponding to the standard, increased from $40 \%$ (12 people) to $66 \%$ (21 people), the indicator fell slightly from $27 \%$ ( 8 people) to $15 \%$ (4 people), the number of students with an increased level of self-confidence increased by 2 (there was $6 \%$ ( 2 persons) with the following increase up to $15 \%$ (4 persons)). And the number of students with a significant "self-confidence" lag was reduced from $27 \%$ (8 people) to $4 \%$ ( 1 person). According to the subscale "Communication development", the diagnosed with the rates corresponded to the standard increased from $30 \%$ ( 9 people) to $67 \%$ (20 people). The number of persons with a slight backlog in 
communication decreased from $27 \%$ ( 8 people) to $10 \%$ (3 persons). The number with standard excess increased from $13 \%$ (4 people) to $23 \%$ (7 people), and the number of schoolchildren who had a significant lag was reduced from 9 people to zero.

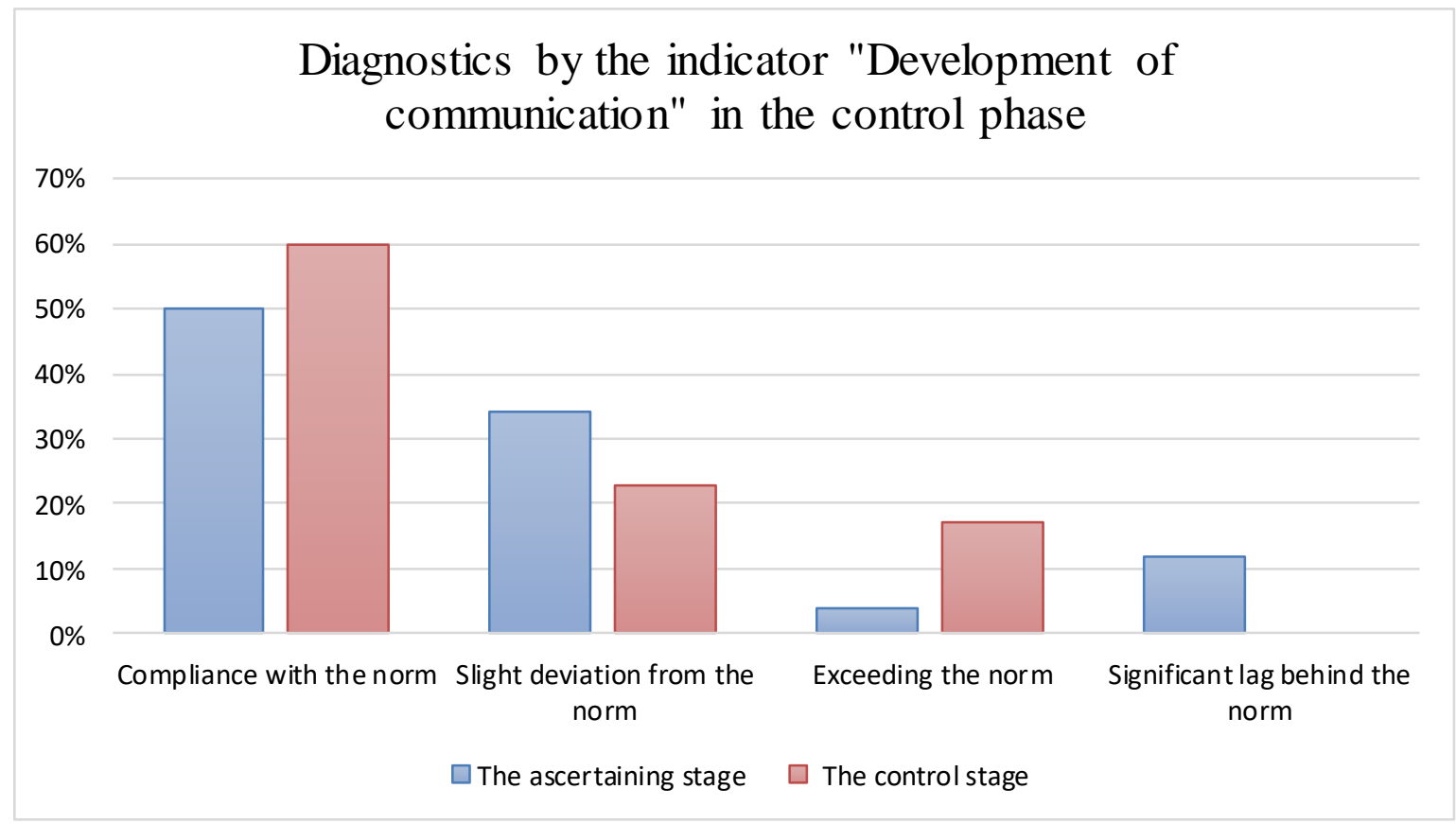

Fig.2.17 - "Social Competence Scale" (A.M. Prikhozhan), subscale "Communication development"

The results for Guildford's "Social Intelligence" according to the subtest "The stories with a supplement" are presented in the diagram below.

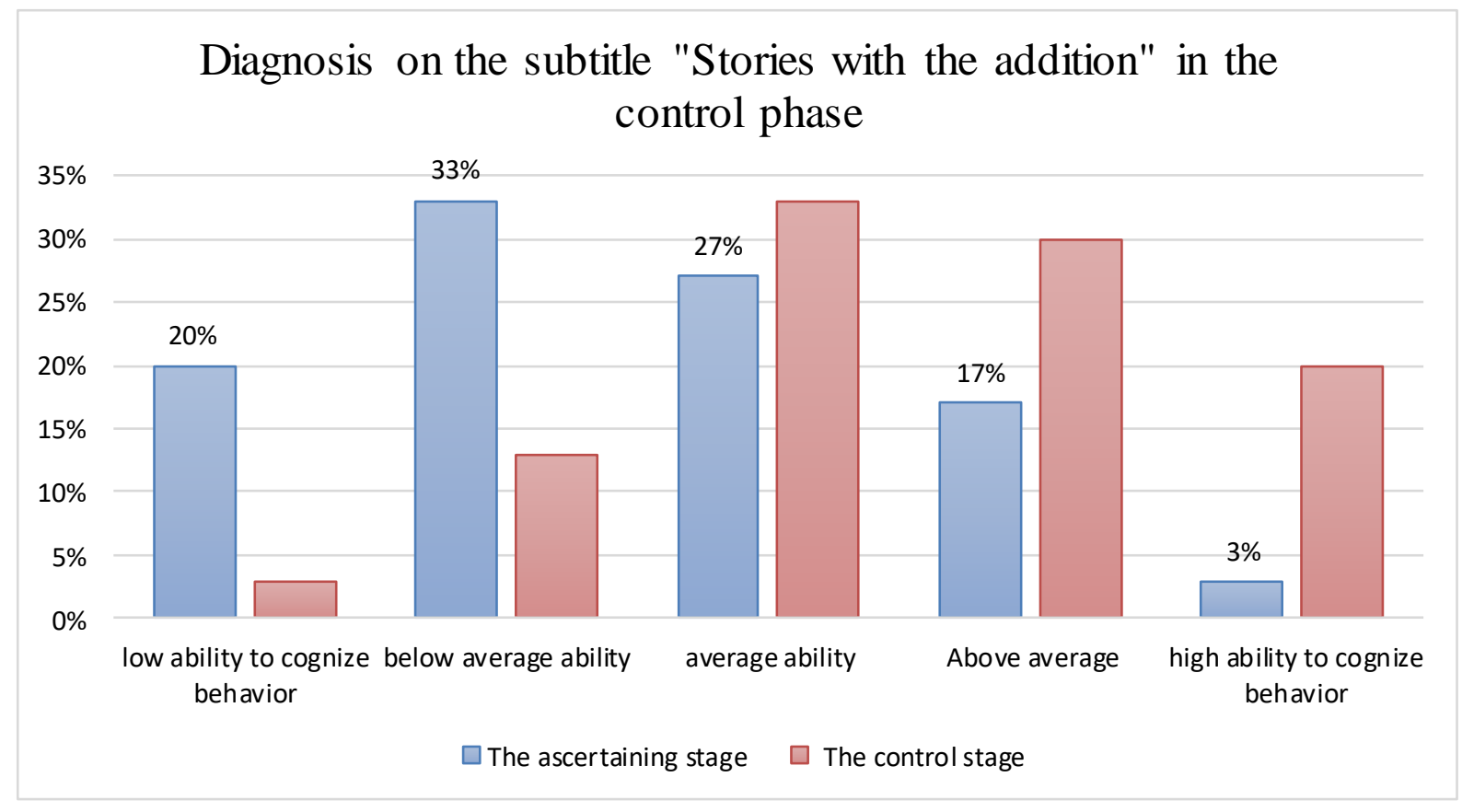

Fig. 2.18 - The Method "Social Intelligence" by J. Guilford

Before the developing program, the results were the following ones: only $3 \%$ (one child) had high abilities to behavior cognition. After that the indicator increased up to $20 \%$ (6 children with high abilities for the cognition of behavior. The rates above-average increased from $17 \%$ ( 5 children) to $30 \%$ ( 9 children),
$27 \%$ ( 8 people) had average abilities, after the Program their amount was 33\% (10 people). $33 \%$ (10 children) had the ability to behavior learning below average, now there are only $13 \%$ ( 4 children) of them. The number of children with low learning abilities decreased from $20 \%$ (6 children) to $3 \%$ ( 1 child). 


\section{Summary}

Thus, we see that three previously lagging indicators improved as the result of our psychological and pedagogical program for the development of social competence "In harmony with oneself and the world". For a more accurate test of the hypothesis, the results for previously lagging indicators were subjected to statistical analysis. We used Student's t-test for dependent samples in order to determine the reliability of the changes using the control experiment

The obtained results of Student's t-test by A.M. Prikhozhan's method (the subscale "Self-confidence"). Result: $\mathrm{t}_{\text {Емп }}=5.8$. (at critical values of $2.05(\mathrm{p} \leq 0.05)$ and $2.76(\mathrm{p} \leq 0.01))$.

According to the method by A.M. Prikhozhan (subscale "Communication development") $t_{\mathrm{Emp}}=3.2$ (for critical values $2(\mathrm{p} \leq 0.05)$ and $2.66(\mathrm{p} \leq 0.01)$ ). According to Guildford's "Social Intelligence" test (the "History with the addition" subtest) $t_{\mathrm{Emp}}=3.62$ $(\mathrm{p} \leq 0.05)$ and $2.66(\mathrm{p} \leq 0.01))$.

Thus, all three cases have reliable differences between the data before and after the implemented program "In harmony with oneself and the world". Accordingly, the proposed hypothesis $\mathrm{H} 1$ on the presence of reliable differences is confirmed. Improved indicators suggest that the hypothesis of our study is confirmed and the goal is achieved. The results of the research lead to the conclusion that the program "In harmony with oneself and the world" developed by us is effective for the development of student social competence.

\section{Acknowledgements}

The work is performed according to the Russian Government Program of Competitive Growth of Kazan Federal University.

\section{References}

1. Boyarsky E.A. Competences: from differentiation to integration / E.A. Boyarsky, S.M. Kolomiets // Higher education today. 2014. - №1. - pp. 8-11.

2. Giyenko L.N. The development of social competence among adolescents / L.N. Gienko // Actual problems of psychology and pedagogy: materials of the regional student scientific-practical conference / ed. by V.G. Babina, V.P. Dolgovykh, N.V. Dolgova, L.V. Chubinidze. - Gorno-Altaisk: the publishing house of Gorno-Altaisk State University. 2011. - pp. 17-22.

3. Dobrolyubov N.A. Social competence of adolescents and their socialization / N.A. Dobrolyubov. - Youth to Barnaul: materials of scientific-practical. conf. - Barnaul: Publishing house of the Altaisk State University, 2005. $53 \mathrm{p}$.

4. Zimnaya I.A. Key competences - a new paradigm for the development of education result / Zimnyaya I.A. // Higher education today. - 2013. - №5. - pp. 34-42.

5. Ivanov L.M. Application of the Netherlands model of social competence increase among adolescents / L.M. Ivanov, E.V. Koneva. Herald of psychological and socialrehabilitation work. - 2001. - №2. - pp. 30-41.

6. Kalinina N.V. The psychology of innovative management by social groups and organizations / N.V. Kalinina. Moscow: Kostroma, 2012. - 146 p.

7. Kydron A. The development of social competence in socio-psychological training / Kidron A. // Psychological conditions of social interaction; Ed. by E. M. Wernick, - Tallinn, 2012. - 99 p.

8. Koblyanskaya E.V. Psychological aspects of social competence: author's abstract from the dis. of psych. sciences candidate / E.V. Koblyanskaya. - St. Petersburg: St. Petersburg State University, 2011. - 19 p.

9. Kolmogorova L.S. Diagnostics of schoolchildren psychological culture. L.S. Kolmogorova. - Volgograd: VLADOS PRESS, 2012. - 360 p.

10. Kunitsyna V.N. Interpersonal communication / Kunitsina V.N. - St. Petersburg: Peter, 2013. $103 \mathrm{p}$.

11. Lukyanova M.I. Social competence as the component of management culture / Lukyanova M.I. - Moscow: Kostroma: KSU named after N.A. Nekrasov, 2001. - 240 p.

12. I.A. Maslova. Socialization of an adolescent in the educational space of additional education institution for children - Orenburg: Bulletin of the Pomor University. - 2014. - № 7. - pp. 415.

13. Sivkova G.I. Social competence / G.I. Sivkova // Vacancy. - 2011. - No. 13. - pp. 98-104. 